\title{
Avaliação do desempenho agronômico de cultivares de girassol (Helianthus annuus L.) no cultivo em safrinha na região Oeste Paulista
}

Evaluation of agronomic performance of sunflower cultivars (Helianthus annuus L.) during the off-season cultivation at the Western São Paulo region

Evaluación del desempeño agronómico de girasol (Helianthus annuus L.) cultivadas en la temporada baja en la región del Oeste Paulista

Elivelton Alves Lustri

Graduado - Curso de Agronomia

Universidade do Oeste Paulista - Unoeste, Brasil elivelton.al@hotmail.com

Beatriz Talielli da Silva

Graduada - Curso de Bacharelado em Ciências Biológicas Universidade do Oeste Paulista - Unoeste, Brasil beatriz.talielli@gmail.com

\section{Douglas Rogério Estevam Peruchi}

Graduando - Curso de Agronomia Universidade do Oeste Paulista - Unoeste, Brasil douglasperuchiusp@gmail.com

Italo Afonso Moura

Graduando - Curso de Agronomia Universidade do Oeste Paulista - Unoeste, Brasil italo.afonso@outlook.com

\section{Antonio Fluminhan}

Professor Doutor - PPG em Meio Ambiente e Desenvolvimento Regional Universidade do Oeste Paulista - Unoeste, Brasil fluminhan@unoeste.br 


\section{RESUMO}

A produção de girassol (Helianthus annuus L.) no Brasil encontra-se em contínua expansão, e tem motivado diversos grupos de pesquisa sobre o assunto. Sabe-se que o desempenho da cultura está diretamente relacionado à escolha da época de semeadura, do genótipo, do manejo adequado do solo e fertilidade, adoção de sistema de rotação e, especialmente, dos fatores ambientais. O presente estudo teve por objetivos avaliar o desempenho de variedades de girassol nas condições de cultivo de safrinha e analisar as vantagens e desvantagens de cada um, de modo a estabelecer condições para a implantação de um programa de melhoramento genético com vistas á selecionar genótipos mais adaptados à região Oeste Paulista. A performance de quinze cultivares desta espécie foi avaliada levando-se em conta os seguintes parâmetros agronômicos: altura de planta, circunferência do caule, número de capítulos por planta, diâmetro médio de capitulo, número de folhas por planta e área foliar média. Os dados obtidos foram submetidos à análise de variância pelo teste de $\mathrm{F}$ e avaliação de médias de Tukey, ao nível de $5 \%$ de probabilidade. Observou-se uma grande variação entre os cultivares, com performances superiores para os cultivares Siamar e Pipoim e inferiores para Argentina II e Avícola Rajada. Este resultado demonstra a viabilidade na adoção de programas de seleção de progênies dos genótipos mais favoráveis, para a avaliação das características fenotípicas mencionadas. Essa pesquisa contribui para a geração de conhecimento básico necessário ao processo de introdução desta espécie nas condições edafo-climáticas de produção agrícola da região Oeste Paulista.

PALAVRAS-CHAVE: Girassol; Melhoramento genético; Desempenho agronômico; Biodiesel; Oleaginosas

\section{ABSTRACT}

The production of sunflower (Helianthus annuus L.) in Brazil is continuously expanding, and has motivated several research groups on the subject. It is known that sunflower crop's performance is directly related to the choice of sowing date, genotype, appropriate soil management and fertility, adoption of a rotation system and especially environmental factors. This study aimed to evaluate the performance of several sunflower cultivars in the offseason cultivation conditions and analyze the advantages and disadvantages of each, in order to set conditions for the implementation of a breeding program with emphasis on the selection of the most adapted cultivar to the Western São Paulo region. The performance of fifteen cultivars was evaluated through an experimental design with three replications. We evaluated the following agronomic parameters: plant height, stem circunference, number of chapters per plant, diameter of chapter, number of leaves per plant and leaf area. The data were submitted to analysis of variance by $\mathrm{F}$ test and evaluation of means by Tukey test at $5 \%$ probability. There was a wide variation among the cultivars with higher performances for Siamar and Pipoim and lower for Argentina II and Avícola Rajada. The results demonstrate the feasibility of adopting progeny program selection of the most favorable genotype for evaluating the phenotypic characteristics mentioned. This research contributes to the generation of basic knowledge necessary for the introduction of this species in the production conditions in the Western São Paulo region.

KEYWORDS: Sunflower; Genetic breeding; Agronomic performance; Biodiesel; Oilseeds.

\section{RESUMEN}

La producción de girasol (Helianthus annuus L.) en Brasil se expande continuamente, y ha motivado a varios grupos de investigación sobre el tema. Se sabe que el rendimiento desta cultura está directamente relacionado con La época de plantio, elección del genotipo, el manejo apropiado del suelo y la fertilidad, la adopción de sistema de rotación de las culturas y los factores ambientales, especialmente la siembra. Este estudio tuvo como objetivo evaluar el rendimiento de variedades de girasol en las condiciones de cultivo fuera de temporada y analizar las ventajas y desventajas de cada uno, con el fin de establecer las condiciones para la implementación de un programa de mejoramiento genético destinado a seleccionar genotipos más adaptados a la región Oeste Paulista. El rendimiento de quince variedades de esta especie se evaluarán teniendo en cuenta los siguientes parámetros agronómicos: altura de la planta, circunferência de caule, número de capítulos por planta, el diámetro médio del capitulo, número de hojas por planta y el área foliar. Los datos fueron sometidos a análisis de varianza mediante la prueba $\mathrm{F}$ y la evaluación de los medios de Tukey al $5 \%$ de probabilidad. Había una gran variación entre los cultivares con prestaciones superiores para Siamar y Pipoim e inferior para Argentina II y cultivares de aves de corral a ráfagas. Este resultado demuestra la viabilidad de adoptar selección de programa progenie del genotipo más favorable para la evaluación de las características fenotípicas mencionados. Esta investigación contribuye a la generación de conocimientos básicos necesarios para la introducción de esta especie en el suelo y las condiciones climáticas de la producción agrícola en el Oeste Paulista región.

PALABRAS CLAVE: Girasol; Mejoramiento genético; Comportamiento agronómico; Biodiesel; Semillas oleaginosas. 


\section{INTRODUÇÃO}

O girassol (Helianthus annuus L.) era utilizado, até meados do século $X X$, apenas para a alimentação animal, para a produção de óleo comestível ou como finalidades ornamentais. Mas, neste século, com os recentes avanços nas pesquisas para uso de bicombustíveis, observou-se que o girassol pode ainda ser ainda mais útil do que já era considerado. Diversas instituições de pesquisa desenvolveram inúmeros cultivares de girassol que passaram por melhoramento genético, e que passaram a ser distribuídos nas diversas regiões de produção agrícola no Brasil. Porém, são poucas as cultivares adaptadas às condições edafo-climáticas específicas da região Oeste Paulista, onde há predominância de solos de textura arenosa, com inverno frio e seco e verão quente e chuvoso.

Existem diversos cultivares de girassol de ciclo precoce, médio e tardio, sendo essas testadas, em grande parte, nas regiões Sul e no cerrado brasileiro. Os cultivares disponíveis no mercado de sementes apresentam finalidades múltiplas, tais como, por exemplo: a) para fins industriais - as que apresentam alto teor de óleo (40\% a $50 \%)$; b) com baixos teores de óleo (30\%), denominados materiais confeiteiros; c) algumas são destinadas a alimentação animal (para a produção de silagem) e, d) aquelas com quantidades elevadas de acido oleico, que são produzidas para atender à demanda da indústria alimentícia.

Para combater o grande problema representado pelo aquecimento global, que por sua vez é causado em parte pelo efeito estufa, a adoção do biodiesel é uma das estratégias mais incentivadas, visando à diminuição do uso de combustíveis fósseis, aliado à sua enorme vantagem de ser um combustível de origem renovável.

Apesar do grande incentivo do governo federal à produção de espécies vegetais oleaginosas, como é o caso do girassol, mamona e pinhão manso, entre outras, tem-se observado que o zoneamento agrícola para fins de obtenção de crédito agrícola tem privilegiado regiões menos desenvolvidas no Nordeste, Centro-Oeste e Norte de Minas Gerais. Deste modo, o resultado observado é desalentador, uma vez que empresas produtoras de óleo vegetal da região são obrigadas a importar a matéria prima de outras regiões do Brasil e até mesmo do exterior.

É importante ressaltar que através da seleção de novos cultivares, a produtividade desta espécie poderá ser aumentada sensivelmente e, portanto, inibindo a necessidade de desmatamento de áreas com vegetação nativa, ou de se substituir áreas produtoras de outras culturas. Ressalte-se o fato que o girassol apresenta várias características que são favoráveis até mesmo para a geração de fontes alternativas de renda como é o caso da produção do mel, o que, segundo diversos autores, também aumenta significativamente a produtividade desta oleaginosa.

Com o crescente aumento da área de cultivo de cana-de-açúcar em substituição às pastagens degradadas na região do Oeste Paulista, há a necessidade de criação de culturas diferenciadas que possam ser economicamente competitivas e possam ser produzidas em sistemas de rotação de culturas, na etapa de renovação dos canaviais. 


\section{Cultivo do girassol no Brasil}

Presume-se que o cultivo de girassol no Brasil iniciou-se na época da colonização, sendo que os primeiros cultivos ocorreram na região Sul. No final do século XIX, a cultura foi trazida pelas primeiras levas de colonos europeus, que consumiam suas sementes torradas e fabricavam uma espécie de chá rico em cafeína, o qual substituía o café no desjejum matinal (PELEGRINI, 1985). A primeira indicação de cultivo comercial foi na data de 1902, em São Paulo quando a Secretaria Estadual de Agricultura distribuiu sementes aos agricultores (GRANATO, 1902, citado por UNGARO, 1982).

Na década de 30 do século $X X$, era divulgado, á semelhança dos dias de hoje, como planta de muitas utilidades, como forrageira e produtora de silagem, melífera, produtora de sementes para a extração de óleo comestível e para a alimentação de aves (GRANATO, 1934, citado por UNGARO, 1982).

Na década de 1960, houve nova tentativa para estimular o cultivo de girassol no Brasil, novamente no Estado de São Paulo, incentivado pelos órgãos do Governo desse Estado. A Secretaria Estadual de Agricultura de São Paulo deu apoio à implantação da cultura e, nos primeiros anos daquela década, a fabricação de óleos vegetais através da empresa Agroindustrial e Comercial Aguapei Ltda., situada na região Noroeste do estado, incentivou o cultivo dessa oleaginosa. No ano agrícola 1964-1965, o girassol atingiu produção superior a 4 mil toneladas de grãos, numa área cultivada de, aproximadamente, 3 mil hectares.

O insucesso da cultura ocorreu, naquela época, por falta de tecnologia adequada e pelo fato das sementes de cultivares e o método de cultivo e manejo da cultura eram os mesmos daqueles utilizados na Argentina. Naquele país, apesar de boa produtividade, os cultivares eram muito sensíveis a doenças, principalmente a ferrugem (Puccinia helianthi) (LASCA, 1993; DALL'AGNOL et al., 1994).

$\mathrm{Na}$ atualidade, os desafios que o girassol ainda enfrenta, no Brasil, segundo Pelegrini (1985) são basicamente três: 1) oferecer aos produtores uma cultura alternativa que, em caráter complementar, possibilite uma segunda colheita, sobre a mesma área e no mesmo ano agrícola; 2) oferecer mais uma matéria-prima oleaginosa ás indústrias de processamento de outros grãos, reduzindo sua ociosidade; e, finalmente, 3) oferecer ao mercado um óleo comestível de alto valor nutritivo. Aliado a esses desafios, deve-se ressaltar a alternativa atual da produção de energia, já que o girassol pode ser utilizado como matéria-prima para a produção de biocombustíveis.

Com os avanços em tecnologia e tratos culturais trazidos pelas atuais pesquisas, observou-se um aumento significativo em produtividade, que gira em torno de $2400 \mathrm{~kg} / \mathrm{ha}$ em condições campo não controlado, desde que as lavouras sejam bem conduzidas (EMBRAPA, 2005).

O girassol é uma cultura com excelentes perspectivas de expansão no Brasil, em função de suas características (ampla adaptação aos diferentes ambientes, qualidade de óleo, tolerância à seca etc.). Para isso, há necessidade de adequá-lo de forma harmônica aos diferentes sistemas de produção relativos às culturas tradicionais, tais como: milho, soja, arroz e outras. Diante destas considerações, os programas de melhoramento genético devem ser direcionados para atingir os seguintes objetivos, (conforme EMBRAPA, 2005): 
- Rendimento de grãos elevado, para torná-lo competitivo, considerando os altos custos de produção que prevalecem no País;

- Alto teor de óleo, uma vez que a política de comercialização prevê uma bonificação para teores acima de determinado valor, que atualmente é de $40 \%$, com tendências de aumento à medida que a cultura se tornar mais expressiva no País;

- Ciclo precoce a médio, para uma perfeita integração aos diferentes sistemas de produção;

- Porte reduzido, bem como uniformidade de altura e floração, para tornar o processo da colheita mais eficiente;

- Resistência a doenças, especificamente a mancha de alternária (Alternaria spp.) e a podridão branca (Sclerotinia sclerotiorum), para garantir melhor estabilidade de produção nas Regiões Sul e Sudeste;

- Tolerância ao excesso de Alumínio, á acidez do solo e a deficiência de Boro, visando atender principalmente à Região Centro-Oeste (SOUZA et al., 2004).

Os primeiros esforços com pesquisa de girassol realizados no Brasil tiveram inicio no Instituto Agronômico de Campinas (IAC), no Estado de São Paulo, em 1937, mas um amplo programa de pesquisa só seria montado em 1972 (UNGARO, 1982). Destacaram-se os programas de melhoramento genético e a condução de trabalhos relativos à nutrição mineral de plantas, espaçamento de cultivo das plantas, controle de pragas, entre outros.

Esses trabalhos resultaram em diversas variedades e no desenvolvimento de tecnologia de produção de girassol no estado de São Paulo, gerando informações que possibilitaram a expansão da cultura (LASCA, 1993; DALL'AGNOL et al, 1994).

A partir de 1989, sob a coordenação da Embrapa Soja (Centro Nacional de Pesquisa da Soja, em Londrina, PR), a pesquisa com essa cultura tomou um novo impulso. Pesquisadores com dedicação exclusiva para pesquisas com girassol foram contratados e, desta forma, a Instituição teve que se organizar para cumprir sua missão, que inclui os seguintes aspectos: a) viabilizar soluções que contribuam para o desenvolvimento dos agronegócios da soja e do girassol, com sustentabilidade do espaço rural, por meio de geração, adaptação e transferência de conhecimentos e tecnologias, b) obter maior estabilidade de produção; c) gerar genótipos mais resistentes a doenças; d) obter mais informações em relação às atividades de manejo do sistema de produção e, e) gerar informações precisas sobre alternativas de diferentes usos dos produtos (alimentação humana, alimentação animal, biocombustíveis e outros) (EMBRAPA, 2005). Em 1997, a Embrapa Soja lançou a variedade Embrapa 122-V2000, proveniente de seleção na variedade Issanka, introduzida da França (CASTIGLIONI et al., 1997).

Além do girassol destinado à extração de óleo, o programa de melhoramento da Embrapa Soja vem desenvolvendo cultivares específicos para o mercado de flores (OLIVEIRA e CASTIGLIONI, 2003). Em 2001, foram registrados vários cultivares de girassol ornamental, com tonalidades de coloração distintas e adaptadas ao Brasil.

Por sua vez, a pesquisa com girassol na Universidade Federal do Rio Grande do Sul (UFRGS) iniciou-se na década de 1950. Já nas décadas de 1960 e 1970, como a área com a cultura 
declinou acentuadamente no Estado do Rio Grande do Sul, os trabalhos experimentais seguiram essa mesma tendência. Em 1980, o setor de Plantas de Lavoura da UFRGS reiniciou os trabalhos experimentais com a cultura, uma vez que já se dispunham de cultivares híbridas no Brasil e de demais informações resultantes de pesquisas realizadas, especialmente nos Estados do Paraná e de São Paulo. Os objetivos gerais da pesquisa foram: a) gerar tecnologias mais adequadas para o cultivo do girassol na região da Depressão Central, no RS; b) determinar a viabilidade técnica da inclusão do girassol nos sistemas de produção, visando à diversificação de culturas e o aumento da eficiência do uso da terra; c) propiciar treinamento dos recursos humanos através da participação de estudantes de graduação e pós-graduação nas atividades de pesquisa (UFRGS, 198_)

\section{Métodos de melhoramento do girassol}

O girassol é uma espécie alógama na qual se percebem dois mecanismos básicos de reprodução: de um lado, a protandria, associada aos caracteres morfológicos das flores; e de outro lado, a ocorrência de um sistema genético de auto-incompatibilidade. Esses dois mecanismos, sobretudo o ultimo, determinam a diferença no nível de auto fecundação de cada genótipo; Portanto, há um gradiente que vai desde a completa auto-incompatibilidade até $100 \%$ de autofertilidade.

Os métodos de melhoramento usados na cultura do milho e de outras culturas alógamas são aplicados na cultura do girassol, com apenas algumas restrições e/ou modificações decorrentes de sua morfologia floral. A aplicação desses métodos visa ao desenvolvimento de cultivares (variedades e híbridos) que são caracterizados pela alta produtividade e estabilidade no desempenho.

O processo de desenvolvimento de cultivares inclui as seguintes etapas:

- obtenção ou desenvolvimento de fontes de variabilidade genética, que devem ser mantidas através de bancos ativos de germoplasma;

- desenvolvimento de cultivares de polinização aberta para uso "per se", tais como populações sintéticas ou compostos genéticos, ou para a extração de linhagens endogâmicas;

- desenvolvimento de linhagens para a produção de híbridos, com respectiva avaliação de sua habilidade de combinação.

Segundo Embrapa (2005) há a necessidade de se obter cultivares que tenham um ciclo curto (precoce), em torno de 120 dias. Há também a necessidade de uma produção conjunta coma apicultura, uma vez que, no caso do girassol, aumentará a produção de aquênios, assim como a produção de mel. Tal como para outras culturas, no girassol também se devem desenvolver cultivares cujas plantas tenham pronunciada resistência ao estresse hídrico, com grande quantidade de sementes em seus capítulos, frutos indeiscentes e com uniformidade na maturação e, em especial, sejam adaptados ao cultivo sob as condições edafo-climáticas da região Oeste Paulista. Deve-se ressaltar que os cultivares deve apresentar associado à grande produtividade de grãos, que este tenha elevados teores de óleo. 
Finalmente, grande importância em se identificar características agronômicas favoráveis dentro das populações de uma mesma espécie, através de várias gerações de seleção, que poderão ser desenvolvidas nos próximos anos agrícolas, a fim de selecionar cultivares que apresentem predominância das características para produção no sistema de cultivo mecanizado. As características agronômicas consideradas ideais para o cultivo mecanizado, visando à produção em larga escala, e que serão utilizados como critérios de seleção de novos cultivares da espécie são: a) plantas com porte baixo; b) colmos estreitos e com poucas ramificações; c) alta produtividade; d) sementes com alto teor de óleo; e) precocidade; f) frutos indeiscentes e com maturação uniforme.

\section{Utilização da espécie do ponto de vista comercial e industrial}

O girassol é uma espécie cultivada com papel muito importante do ponto de vista comercial e industrial. O seu óleo é utilizado na alimentação humana, onde é muito recomendado, principalmente para a prevenção de doenças do coração (EMBRAPA, 1980, LASCA, 1993). Na área industrial, o seu potencial para a produção de biodiesel é amplamente reconhecido (CATI, 1988).

O aquecimento global, provocado pelo efeito estufa, vem causando graves alterações no ecossistema terrestre. O dióxido de carbono, principal causador deste efeito, é liberado em grandes quantidades na atmosfera como resultado da combustão, sendo que a utilização de combustíveis fósseis agrava o problema, uma vez que libera o carbono que estava fixado há milhões de anos nas jazidas de petróleo. A preocupação com os efeitos climáticos que comprovadamente são consequências do uso indiscriminado de combustíveis fósseis tem gerado discussões para a busca de fontes alternativas de energia.

\section{OBJETIVOS}

A presente pesquisa teve por objetivos: a) avaliar o desempenho de diversos cultivares de girassol nas condições de cultivo de safrinha; $b$ ) analisar quais são as vantagens e desvantagens de cada cultivar, de modo a favorecer a implantação de um programa de melhoramento genético com vistas á selecionar os mais adaptados à região Oeste Paulista; c) formar um banco de germoplasma da espécie, através da obtenção de materiais genéticos disponibilizados por instituições de pesquisa e empresas produtoras e distribuidoras de sementes na região Oeste Paulista; d) realizar uma análise comparativa entre os genótipos mais favoráveis, utilizando como critérios de avaliação as características fenotípicas tais como: altura de plantas, número de capítulos, diâmetro médio de capítulo, área foliar, número de folhas, circunferência do caule; e e) finalmente, avaliar dados biométricos necessários para a realização de ensaios de competição dos cultivares selecionados, confrontando-os com os desempenhos dos outros cultivares disponíveis no mercado. 


\section{MATERIAL E METODOLOGIAS}

Os materiais biológicos avaliados consistiram de quinze (15) cultivares utilizados pelos agricultores da região de Presidente Pudente - SP, e que estão listados a seguir:

$\begin{array}{lll}\text { Andrés } & \text { Avicultura Grande } & \text { Pitucão Preta } \\ \text { Argentina II } & \text { Avicultura Rajada } & \text { Pitucão Rajada } \\ \text { Avícola Cinza } & \text { Ducão Gigante } & \text { Siamar } \\ \text { Avícola Preta } & \text { Ducão Miúdo } & \text { Tóri } \\ \text { Avícola Rajada } & \text { Graúdo } & \text { Pipoim }\end{array}$

As sementes dos materiais avaliados foram obtidas através da aquisição no mercado, sendo que a grande maioria dos materiais não possui identificação de sua procedência, número de registro ou código de identificação do material e, muitas vezes, não são classificados como "sementes", e sim como "grãos", inclusive de origem em outros países da América do Sul. Optou-se por esta estratégia justamente para viabilizar a identificação de fonte de germoplasma com a máxima variabilidade genética e morfológica possível, que foram evidenciadas através das características fenotípicas das sementes das mesmas.

\section{Área experimental e delineamento empregado}

A avaliação do desempenho dos cultivares foi realizada na área agrícola localizada no Campus Il da UNOESTE, na cidade de Presidente Prudente (SP). Esta região apresenta um clima considerado subtropical, com inverno rigoroso seco e bem definido e verão quente e chuvoso. O plantio foi realizado em um delineamento inteiramente casualizado, com um total de três repetições dos 15 cultivares empregados. Cada parcela apresentou as dimensões: quatro linhas de $4 \mathrm{~m}$ de comprimento, e espaçamento entre linhas de $0,9 \mathrm{~m}$, sendo mantida a distância de $0,2 \mathrm{~m}$ entre plantas.

Para a coleta de dados, foram consideradas apenas as duas linhas do interior de cada parcela, e descartadas as linhas laterais (bordaduras). Além disto, foram desconsideradas as plantas existentes nas bordas da frente e fundo ( $0,5 \mathrm{~m}$ de comprimento) de cada uma destas duas linhas internas. Portanto, a área útil de cada parcela ficou restrita a duas linhas de 3,0m de comprimento cada uma, perfazendo um total de $8 \mathrm{~m}$ lineares de plantas ou 40 plantas.

\section{Preparo da área de cultivo e tratos culturais}

O preparo do solo foi realizado segundo o método convencional. Inicialmente, para o controle de plantas daninhas, foi empregado o herbicida Glifosato que é um herbicida não seletivo, de ação pós-emergente, e que apresenta como um concentrado solúvel. Foi efetuado o controle das plantas daninhas cerca de 3 semanas antes da instalação da cultura.

Este herbicida foi utilizado em dosagem de $500 \mathrm{ml}$ do produto para 40 litros de água, aplicados com o auxílio de pulverizador costal. Após a aplicação do herbicida ocorreu gradação, para 
incorporação de matéria orgânica, controle de erosão, e limpeza geral do espaço de cultivo. A semeadura da cultura foi efetuada em condições de "safrinha", no início de maio de 2015.

Com base nas recomendações do Boletim Técnico 100 do Instituto Agronômico de Campinas (IAC), seguindo a recomendação de adubação de base, ou de plantio, com a utilização do adubo químico na formulação 08-28-16, aplicando-se $300 \mathrm{~kg} / \mathrm{ha}$, e adubação de cobertura com Uréia (equivalente a $50 \mathrm{~kg} \mathrm{~N} / \mathrm{ha}$ ), dividida em duas aplicações: uma aos 30 dias e a segunda aos 45 dias após a emergência das plantas. Foram também efetuados os tratos culturais convencionais, procurando com isso a menor utilização possível de insumos químicos, visando à menor poluição ao meio ambiente.

\section{Parâmetros de comparação entre variedades e coleta de dados}

A avaliação comparativa dos 15 cultivares de girassol envolveu a análise de diferentes características morfométricas de importância agronômica, e que serviram para a seleção dos materiais mais promissores para o melhoramento genético da espécie, tais como: altura de plantas, número de capítulos por planta, diâmetro médio de capítulo, área foliar, número de folhas, circunferência do caule. Esses parâmetros biológicos foram coletados após as plantas atingirem a maturidade, ou, seja, após o seu florescimento cerca de 60 a 70 dias após a germinação e emergência, como mostrado na Figura 1. A coleta foi realizada com o emprego de fitas métricas, trenas de campo, contagem visual, sendo os dados anotados em fichas de avaliação de cada cultivar.

\section{Análises estatísticas}

Os dados obtidos foram submetidos à verificação da dispersão para determinação da normalidade e submetidos à análise de variância pelo teste de $\mathrm{F}$, aos níveis de $1 \%$ e $5 \%$ de probabilidade. As análises estatísticas foram realizadas através do programa estatístico ASSISTAT $^{\circ}$ (com referências em SILVA, 1996; SILVA e AZEVEDO, 2002; 2006; 2009). Quando o valor de $\mathrm{F}$ foi significativo ao nível de $5 \%$ de probabilidade, foi realizado o teste de Tukey por meio do mesmo programa estatístico, para a comparação de contrastes entre médias dos indivíduos.

Como medida de dispersão dos dados, foram calculados os coeficientes de variação (C.V.) para cada característica avaliada. Para que não ocorrer desvios nas análises estatísticas devido à presença de valores iguais a zero, foi aplicada a transformação dos dados através da fórmula: raiz quadrada de $\mathrm{P}+0,5$, sendo $\mathrm{P}=$ valor coletado para o parâmetro analisado. 
FIGURA 1 - Aspectos gerais da área experimental localizada no Campus II da UNOESTE, após a implantação dos experimentos com girassol, com a coleta dos dados biométricos de desempenho agronômico envolvidos na presente pesquisa,

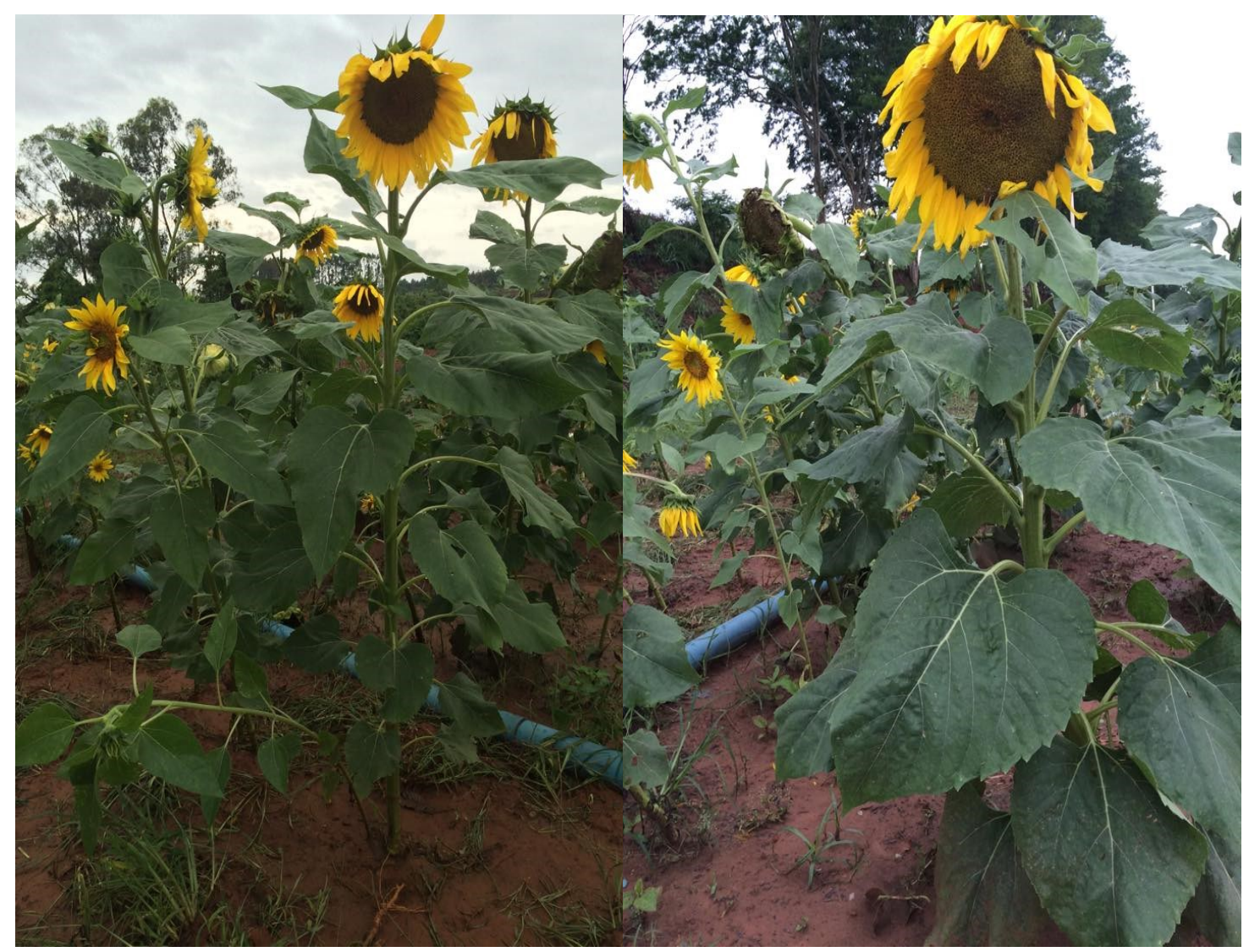

\section{RESULTADOS E DISCUSSÃO}

Fonte: Os autores

As análises de variância, referentes aos diferentes parâmetros de comportamento agronômico dos genótipos de girassol cultivados nas condições da região Oeste Paulista, envolvidos na presente pesquisa, estão sumarizadas na Tabela 1. 
TABELA 1 - Resumo da análise de variância (ANOVA) para os parâmetros: altura de planta (ALT) $(\mathrm{cm})$, número de folhas (NFOL), área foliar $(\mathrm{AFOL})\left(\mathrm{cm}^{2}\right)$, diâmetro do capítulo (DCAP) $(\mathrm{cm})$, número de capítulos por planta (NCAP) e circunferência do caule (CCAU) $(\mathrm{cm})$, dos cultivares de girassol avaliados em cultivo de safrinha na região do Oeste Paulista.

\begin{tabular}{lccccccc}
\hline Fonte de & \multirow{2}{*}{$\begin{array}{l}\text { G.L. } \\
\text { Variação }\end{array}$} & & \multicolumn{7}{c}{ Q.M. } \\
\cline { 3 - 7 } & & ALT & NFOL & AFOL & DCAP & NCAP & CCAU \\
\hline Cultivares & 14 & $1,965^{* *}$ & $52,977^{* *}$ & $395,364^{* *}$ & $23,188^{* *}$ & $2,098^{* *}$ & $10,660^{* *}$ \\
Repetições & 2 & $0,069^{\text {ns }}$ & $2,607^{\text {ns }}$ & $35,119^{\text {ns }}$ & $1,306^{\text {ns }}$ & $0,181^{\text {ns }}$ & $1,049^{\text {ns }}$ \\
Cultiv x Rep & 28 & $0,358^{\text {ns }}$ & $0,538^{* *}$ & $11,886^{\text {ns }}$ & $0,363^{\text {ns }}$ & $0,179^{\text {ns }}$ & $0,208^{* *}$ \\
\hline Total & 539 & & & & & & \\
& & & & & & & \\
C.V. (\%) & - & 54,21 & 47,98 & 59,40 & 42,70 & 39,10 & 39,12 \\
\hline
\end{tabular}

G.L.= graus de liberdade; Q.M.=quadrado médio; C.V.=coeficiente de variação.

** = significativo ao nível de $1 \%$ de probabilidade $(p<0,01)$

ns $=$ não significativo $(p<0,05)$

Como pode ser observado, houve efeito significativo dos genótipos para todos os parâmetros morfométricos indicadores de desempenho agronômico avaliados. Foi possível observar, ainda, que os efeitos entre as diferentes repetições não foram significativos em nenhum dos parâmetros avaliados, o que demonstra a eficiência do tipo de delineamento experimental empregado. Entretanto, foi observado que os valores do coeficiente de variação calculados podem ser considerados relativamente elevados, demonstrando a grande variação existente entre plantas de cada parcela.

Resultados semelhantes a estes foram também descritos por PORTO et al. (2007), quando avaliados cultivares de girassol em área agrícola localizada em região subtropical do Brasil, demonstrando a viabilidade no emprego da avaliação de cultivares como etapa precursora de um programa de melhoramento genético de uma espécie de importância agronômica.

A análise de médias apresentada na Tabela 2 ilustra de forma abrangente os resultados obtidos e permite uma análise comparativa mais compreensiva. 
TABELA 2 - Comparação de médias pelo teste de Tukey a $5 \%$ de probabilidade para os diferentes parâmetros de desempenho agronômico avaliados.

\begin{tabular}{|c|c|c|c|c|c|c|}
\hline Cultivares & $(\mathrm{ALT})$ & (NFOL) & (AREF) & (CCAU) & (NCAP) & (DCAP) \\
\hline Andrés & $1,119^{\mathrm{abcd}}$ & $3,792^{\mathrm{bcd}}$ & $9,436^{\mathrm{abc}}$ & $2,271^{\mathrm{abcd}}$ & $1,183^{\text {cdef }}$ & $2,573^{\text {cde }}$ \\
\hline Argentina II & $1,345^{\mathrm{abc}}$ & $1,585^{f}$ & $1,673^{f}$ & $1,072^{\mathrm{g}}$ & $0,859^{f}$ & $1,176^{\mathrm{g}}$ \\
\hline Avícola Cinza & $1,584^{\mathrm{a}}$ & $3,155^{\text {cde }}$ & $6,503^{\text {cde }}$ & $1,848^{\text {cdef }}$ & $1,250^{\text {bcde }}$ & $2,190^{\text {def }}$ \\
\hline Avícola Preta & $1,157^{\mathrm{abcd}}$ & $4,045^{b c}$ & $4,629^{b c d}$ & $1,543^{\text {bcde }}$ & $1,613^{\mathrm{ab}}$ & $2,841^{b c d}$ \\
\hline Avícola Rajada & $0,089^{\text {cd }}$ & $2,067^{e f}$ & $3,557^{\text {ef }}$ & $1,295^{\mathrm{fg}}$ & $0,910^{\text {ef }}$ & $1,505^{\mathrm{abc}}$ \\
\hline Avicultura Grande & $1,062^{\mathrm{bcd}}$ & $3,323^{\text {cde }}$ & $6,602^{\text {cde }}$ & $1,789^{\mathrm{def}}$ & $1,062^{\text {cdef }}$ & $2,319^{\text {def }}$ \\
\hline Avicultura Rajada & $1,086^{\mathrm{abcd}}$ & $4,936^{\mathrm{ab}}$ & $10,320^{\mathrm{ab}}$ & $2,600^{a b}$ & $1,277^{\text {bcde }}$ & $3,285^{a b c}$ \\
\hline Ducão Gigante & $1,392^{\mathrm{abc}}$ & $3,323^{\text {cde }}$ & $7,444^{\mathrm{bcd}}$ & $1,884^{\text {cdef }}$ & $1,109^{\text {cdef }}$ & $2,668^{\text {cde }}$ \\
\hline Ducão Miúdo & $0,971^{\mathrm{cd}}$ & $2,630^{\text {def }}$ & $5,437^{\mathrm{de}}$ & $1,583^{\mathrm{efg}}$ & $0,973^{\text {def }}$ & $1,898^{\text {efg }}$ \\
\hline Graúdo & $1,287^{\mathrm{abcd}}$ & $4,873^{a b}$ & $9,620^{\mathrm{abc}}$ & $2,388^{\mathrm{abcd}}$ & $1,297^{\mathrm{bcd}}$ & $3,278^{a b c}$ \\
\hline Pitucão Preta & $0,941^{\text {cd }}$ & $2,620^{\text {def }}$ & $4,629^{\text {def }}$ & $1,543^{\text {efg }}$ & $1,139^{\text {cdef }}$ & $1,814^{\text {efg }}$ \\
\hline Pitucão Rajada & $0,984^{\text {cd }}$ & $2,696^{\text {cdef }}$ & $4,561^{\text {def }}$ & $1,470^{\mathrm{fg}}$ & $1,555^{\text {cdef }}$ & $1,810^{\text {efg }}$ \\
\hline Siamar & $1,150^{\mathrm{abcd}}$ & $5,516^{\mathrm{a}}$ & $12,943^{\mathrm{a}}$ & $2,673^{\mathrm{ab}}$ & $1,750^{\mathrm{a}}$ & $3,717^{\mathrm{a}}$ \\
\hline Tóri & $1,557^{\mathrm{ab}}$ & $4,888^{a b}$ & $9,931^{\mathrm{abc}}$ & $2,468^{\mathrm{abc}}$ & $1,295^{b c d}$ & $3,300^{\mathrm{abc}}$ \\
\hline Pipoim & $0,814^{d}$ & $4,999^{\mathrm{ab}}$ & $12,939^{\mathrm{a}}$ & $2,882^{\mathrm{a}}$ & $1,387^{\mathrm{abc}}$ & $3,667^{a b}$ \\
\hline
\end{tabular}

$a b c=$ cultivares que teve maiores valores e as defg=cultivares que tiveram menores valores.

(ALT) altura de plantas, (NFOL) número de folhas, (AREF) área foliar, (CCAU) circunferência do caule, (NCAP) numero de capítulos por planta, (DCAP) diâmetro do capitulo.

A avaliação de genótipos em função dos diferentes ambientes é importante para selecionar os cultivares mais adaptadas a cada região (CASTIGLIONI et al., 1995). Sendo assim, pode-se observar a grande variação existente entre os cultivares, conforme pôde ser observado nas análises de médias pelo teste de Tukey descritas anteriormente. Para os parâmetros agronômicos avaliados, foram notadas as seguintes variações entre os cultivares:

Altura de plantas: Foi observado que os cultivares Avícola Cinza e Tori (ciclo precoce) mostraram plantas com valores mais elevados do que os outros cultivares.

Numero de Folhas por Planta: Foi observado que os cultivares Siamar, Pipoim, Avicultura Rajada, Tori e Graúdo (ciclo precoce) mostraram plantas com valores mais elevados do que os outros cultivares (ciclo médio). 
Área Foliar: Foi observado que os cultivares Siamar, Pipoim, Avicultura Rajada (ciclo precoce) mostraram plantas com valores mais elevados do que os outros cultivares (ciclo médio).

Diâmetro de Capitulo: Foi observado que os cultivares Siamar e Pipoim (ciclo precoce) apresentaram valores mais elevados do que os outros cultivares (ciclo médio).

Número de Capítulos por Planta: Foi observado que os cultivares Siamar e Avícola preta (ciclo precoce) mostraram plantas com valores mais elevados do que os outros cultivares (ciclo médio).

Circunferência do Caule: foi observado que os cultivares Pipoim e Siamar mostraram valores mais elevados em comparação aos outros cultivares.

Com relação à precisão experimental, que pôde ser avaliada pelo coeficiente de variação, foi constatada grande variação para os diferentes parâmetros avaliados. Maior precisão experimental ocorreu para o parâmetro "número de capítulos" (CV=39,10), seguido da "circunferência do caule" $(\mathrm{CV}=39,12)$. Devido à grande variação encontrada entre os cultivares, e entre plantas de um mesmo cultivar, é natural que tenham sido observados valores de CV\% superiores a $30 \%$, em consonância com outras observações relatadas na literatura (OLIVEIRA et al., 2001; PORTO et al., 2007; GRUNVALD et al., 2008; PORTO et al., 2009; PIVETTA et al., 2012; NUNES et al., 2013). Para os parâmetros que apresentaram valores de CV\% superiores a $50 \%$ (altura de plantas e área foliar), a precisão pode ser considerada baixa, embora não tenha dificultado a detecção de efeito significativo de diferenças entre genótipos pelo teste utilizado. Nesse aspecto, é recomendável aumentar o número de repetições em trabalhos futuros; sobretudo em experimentos de campo, onde existe uma forte interação genótipo e ambiente.

\section{CONCLUSÃO}

A presente pesquisa revelou o evidente sucesso no ensaio realizado com os quinze cultivares de girassol, visando a avaliação do desempenho agronômico no cultivo em safrinha na região do Oeste Paulista. Pode-se concluir que a presente pesquisa pode subsidiar a recomendação de cultivares, que se adaptaram a região, bem como avaliar a performance dos mesmos dentro dos parâmetros avaliados. A análise do desempenho agronômico dos genótipos de girassol contribui para a geração de conhecimento básico necessário ao processo de introdução desta espécie nas condições edafo-climáticas de produção agrícola da região do Oeste Paulista.

Dessa forma, observa-se que há a necessidade premente da seleção de características favoráveis da oleaginosa para o seu cultivo em larga escala na região. Esta etapa de seleção deverá ser realizada nos próximos anos agrícola. Acredita-se que o estímulo à produção desta espécie poderá reduzir a atual dependência por matérias primas oriundas de outras regiões além de estimular a produção de biodiesel, em substituição às fontes de energia de origem fóssil, e gerando novos empregos no setor agropecuário regional. 


\section{REFERÊNCIAS}

CASTIGLIONI, V. B. R.; LEITE, R. M. V. B. C.; OLIVEIRA, M.F de. Uso de gerações precoces na avaliação de linhas de girassol. In: CONGRESSO NACIONAL DE GENETICA, 41., 1995, Caxambu. Resumos. Caxambu: Sociedade Brasileira de Genética, 1995.p.108.

CASTIGLIONI, V. B. R.; LEITE, R. M. V. B. C.; OLIVEIRA, M.F de Variedade de Girassol - V2000. Londrina: CNPSo, 1997. 1 folder.

CATI - COODENADORIA DE ASSISTÊNCIA TÉCNICA INTEGRAL. Oleaginosas no Estado de São Paulo:Análise e diagnostico. Subsídios da Comissão Técnica de Oleaginosas da Secretaria da Agricultura e Abastecimento. Campinas, 1988. 39p. (CATI. Documentos técnico, 107).

DALL'AGNOL, A.; CASTIGLIONI, V.B.R.; TOLEDO, J.F.F. A cultura do girassol no Brasil. In:PUIGNAU, J. (Ed.) Mejoramiento genético del girassol. Montevideo: IICA, PROCISUR, 1994. p.37-41.(Dialogo,41).

EMBRAPA. Centro Nacional de Pesquisa de Soja. Subsídios para a elaboração do Programa Nacional de Pesquisa de Girassol. Londrina, 1980. 17p.

EMBRAPA. Centro Nacional de Pesquisa de Soja. Girassol no Brasil / editores, Regina Maria Villas Boas de Campos Leite, Alexandre Magno Brighenti, César de Castro. - Londrina: Embrapa Soja, 2005.

GRUNVALD, A.K.; CARVALHO, C.G.P; OLIVEIRA, A.C.B; ANDRADE, C.A.B/ Adaptabilidade e estabilidade de genótipos de girassol no Brasil Central. Pesquisa Agropecuária Brasileira, Brasília, v.43, n.11, p.14831493, nov. 2008.

LASCA, D.H.C. Produção de girassol em São Paulo. In: REUNIÃO NACIONAL DE PESQUISA DE GIRASSOL, 10. 1993, Goiânia. Resumos...Campinas: IAC, 1993. P. 9-11.

NUNES, B.T.; PILON, A.; FLUMINHAN, A. Avaliação do desempenho agronômico de genótipos de girassol (Helianthus annuus L.) cultivados na região Oeste Paulista e análise do rendimento de óleo, matéria seca e proteína bruta. Periódico Eletrônico Fórum Ambiental da Alta Paulista, v.9, n.1, p. 150-165, 2013.

OLIVEIRA, M.F. de; ARIAS, C.A.A.; CARVALHO, C.G.P. de; CASTIGLIONI, V.B.R.; VIEIRA, O.V. Informes da avaliação de genótipos de girassol, 2000/2001 e 2001. Documentos 174. - Londrina: Embrapa Soja, 2001

OLIVEIRA, M.F. de; CASTIGLIONI, V.B.R. Girassol ornamental. Londrina: Embrapa Soja, 2003. 1 folder.

PELEGRINI, B. Girassol: uma planta que das Américas conquistou o mundo. São Paulo: Ícone, 1985.117p.

PIVETTA, L.G; GUIMARÃES, V.F; FIOREZE, S.L; CASTOLDI, C./ Avaliação de híbridos de girassol e relação entre parâmetros produtivos e qualitativos. Ciência Agronômica, v. 43, n. 3, p. 561-568, jul-set, 2012

PORTO, W.S.; CARVALHO, C.G.P. de., PINTO. R.J.B., Adaptabilidade e estabilidade como critérios para seleção de genótipos de girassol. Pesquisa Agropecuária Brasileira, Brasília, v.42, n.4, p.491-499, abr. 2007.

PORTO, W.S.; CARVALHO, C.G.P.de., PINTO.R.J.B. OLIVEIRA, M.F, OLIVEIRA, A.C.B, Adaptabilidade e estabilidade de genótipos de girassol para a região subtropical do Brasil. Ciencia rural, Santa Maria, v.39, n.9, p.2452-2459, dez. 2009. 
SILVA, F. de A. S. e. The ASSISTAT Software: statistical assistance. In: INTERNATIONAL CONFERENCE ON COMPUTERS IN AGRICULTURE, 6, Cancun, 1996. Anais... Cancun: American Society of Agricultural Engineers, 1996. p.294-298.

SILVA, F. de A. S. e. \& AZEVEDO, C. A. V. de. Versão do programa computacional Assistat para o sistema operacional Windows. Revista Brasileira de Produtos Agroindustriais, Campina Grande, v.4, n.1, p.7178, 2002.

SILVA, F. de A. S. e. \& AZEVEDO, C. A. V. de. A New Version of TheAssistat-Statistical Assistance Software. In: WORLD CONGRESS ON COMPUTERS IN AGRICULTURE, 4, Orlando-FL-USA: Anais... Orlando: American Society of Agricultural and Biological Engineers, 2006. p.393-396.

SILVA, F. de A. S. e. \& AZEVEDO, C. A. V. de. Principal Components Analysis in the Software AssistatStatistical Attendance. In: WORLD CONGRESS ON COMPUTERS IN AGRICULTURE, 7, Reno-NV-USA: American Society of Agricultural and Biological Engineers, 2009.

SOUZA, A. de. OLIVEIRA, M.F de, CLASTIGLIONI, V.B.R/ O boro na cultura do girassol./Semina: Ciências Agrárias, Londrina, v. 25, n. 1, p. 27-34, jan./mar. 2004

UNGARO, M.R.G. O girassol no Brasil. O agronômico, Campinas, v.34, p.43-62, 1982.

UFRGS - UNIVERSIDADE FEDERAL DO RIO GRANDE DO SUL. Faculdade de Agronomia. Departamento de Fitotecnia. Setor de Plantas de Lavoura. A pesquisa com girassol. Porto Alegre, 198-. 12p. 1 folder. 